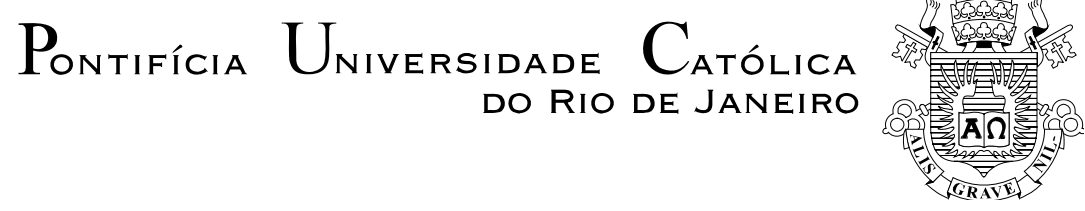

Ana Paula Queiroga Monteiro

Quem Prevê Melhor as Taxas de Juros:

Operadores ou Economistas?

Dissertação apresentada ao Programa de Pós-Graduação em Administração de Empresas da PUC-Rio como requisito parcial para obtenção do título de Mestre em Administração de Empresas.

Orientador: Prof. André Luiz Carvalhal da Silva

Rio de Janeiro

Março de 2011 


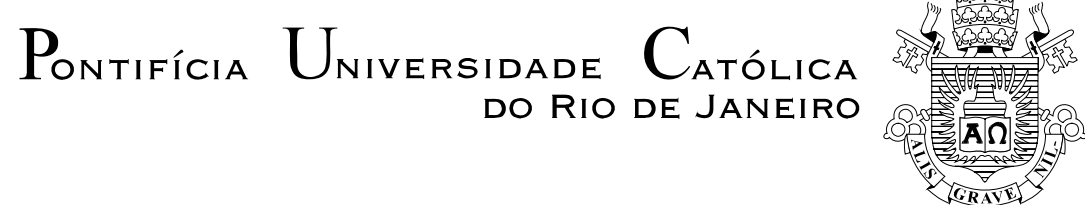

Ana Paula Queiroga Monteiro

\section{Quem Prevê Melhor as Taxas de Juros: \\ Operadores ou Economistas?}

Dissertação apresentada como requisito parcial para obtenção do grau de Mestre pelo Programa de Pósgraduação em Administração de Empresas da PUC-Rio. Aprovada pela Comissão Examinadora abaixo assinada.

Prof. André Luiz Carvalhal da Silva

Orientador

Departamento de Administração - PUC-Rio

Prof. Luiz Felipe Jacques da Motta Departamento de Administração - PUC-Rio

Prof. Márcio Silva de Araujo

Banco Central do Brasil

Prof ${ }^{\text {a }}$. Mônica Herz

Vice-Decana de Pós-Graduação do CCS

Rio de Janeiro, 17 de março de 2011 
Todos os direitos reservados. É proibida a reprodução total ou parcial do trabalho sem autorização da universidade, da autora e do orientador.

\section{Ana Paula Queiroga Monteiro}

Graduou-se em Administração de Empresas pela Universidade do Estado do Rio de Janeiro no ano de 1997. Concluiu o curso de Especialização em Administração - MBA em Finanças Corporativas (IAG PUC-Rio) em 1998. Entre 1996 e 2000 ingressou na Shell Brasil S.A. onde atuou nas áreas comercial e de produtos de Aviação. Foi admitida em concurso público para o Banco Central do Brasil em 2000. Atuou no Departamento Econômico (DEPEC) até 2006. Desde 2006 atua no Departamento de Mercado Aberto (DEMAB) na Consultoria de Desenvolvimento do Mercado Aberto.

Ficha Catalográfica

Monteiro, Ana Paula Queiroga

Quem prevê melhor as taxas de juros : operadores ou economistas? / Ana Paula Queiroga Monteiro ; orientador: André Luiz Carvalhal da Silva. - 2011.

49 f. ; $30 \mathrm{~cm}$

Dissertação (mestrado) - Pontifícia Universidade Católica do Rio de Janeiro, Departamento de Administração, 2011.

Inclui bibliografia

1. Administração - Teses. 2. Previsões. 3. Expectativas. 4. Pesquisa de mercado. 5. Mercado futuro de taxas de juros. 6. Operadores. 7. Economistas. I. Silva, André Luiz Carvalhal da. II. Pontifícia Universidade Católica do Rio de Janeiro. Departamento de Administração. III. Título. 
À minha família, por todo apoio e paciência. 


\section{Agradecimentos}

A Deus, meu protetor.

Ao meu orientador André Carvalhal, pela oportunidade de aprendizado, confiança e paciência.

Aos meus pais, minha irmã e cunhado, ao meu pequeno sobrinho Bernardo, pela força, apoio e paciência quando na minha ausência pelos estudos.

Ao meu namorado, Luiz Eduardo, pela constante força e incentivo sem o qual seria muito difícil prosseguir.

Aos professores do IAG PUC-Rio pelos ensinamentos.

Aos colegas do Banco Central do Brasil, em especial Rosana e André, pelo conhecimento compartilhado.

Aos funcionários da Secretaria pelo esclarecimento de intermináveis dúvidas.

Ao Banco Central do Brasil pelo apoio na concessão de licença capacitação, sem a qual seria difícil concluir essa dissertação. 


\section{Resumo}

Monteiro, Ana Paula Queiroga; Silva, André Luiz Carvalhal (Orientador). Quem Prevê Melhor as Taxas de Juros: Operadores ou Economistas?* Rio de Janeiro, 2011. 49p. Dissertação de Mestrado Departamento de Administração, Pontifícia Universidade Católica do Rio de Janeiro.

As taxas de juros representam uma das variáveis macroeconômicas mais importantes, em especial para a condução da política monetária, ao influenciar diretamente na determinação do custo do dinheiro e na formação de preço de diversos produtos financeiros. Embora tenham sido desenvolvidos modelos de previsão de taxas de juros, pouco ainda se apurou no sentido da medição da capacidade preditiva das expectativas dos agentes de mercado quanto à taxa de juros e sua interação com as taxas de juros futuros praticadas no mercado de derivativos no Brasil. Nesse contexto surge o questionamento de quem prevê melhor a taxa de juros: economistas, que estudam a economia e são responsáveis pelas previsões das expectativas de mercado, ou operadores, que atuam na economia e determinam o patamar das taxas no mercado futuro de taxas de juros? Os resultados obtidos apresentam evidências de que, excetuando-se o período em que ocorre elevação de juros, as expectativas de mercado dos economistas, em geral, têm melhor capacidade preditiva das taxas de juros.

\section{Palavras-chave}

Previsões; Expectativas; Pesquisa de mercado; Mercado futuro de taxas de juros; Operadores; Economistas.

\footnotetext{
* Este trabalho não deve ser citado como representando as opiniões do Banco Central do Brasil. As opiniões expressas neste trabalho são exclusivamente da autora e não refletem, necessariamente, a visão do Banco Central do Brasil.
} 


\section{Abstract}

Monteiro, Ana Paula Queiroga; Silva, André Luiz Carvalhal (Advisor). Who Forecasts Interest Rates Better: Traders or Economists?* Rio de Janeiro, 2011. 49p. MSc. Dissertation - Departamento de Administração, Pontifícia Universidade Católica do Rio de Janeiro.

Interest rates are one of the most important macroeconomic variables, especially for the conduction of monetary policy, directly influencing the cost of money and the pricing of several financial products. Although some predictive models of interest rates have been developed, little is found towards the measurement of the predictive capability of market agents' expectations to interest rates and its interaction with interest rate futures negotiated in the derivatives market in Brazil. This dissertation analyzes who forecasts interest rates better: economists, who study the economy and forecasts market expectations of interest rates, or traders, who act in the economy and determine the level of rates in the interest rate futures market? The results provide evidence that, except for the period in which interest rates rise, market expectations of economists, in general, has better predictive power of future interest rates.

\section{Keywords}

Forecast; Expectations; Market research; Interest rate futures market; Traders; Economists.

\footnotetext{
* The study should not be reported as representing the views of the Banco Central do Brasil. The views expressed in the study are those of the author and not necessarily reflect those of the Banco Central do Brasil.
} 


\section{Sumário}

1. Introdução 13

2. Revisão Bibliográfica $\quad 15$

2.1. Taxas de juros e a Taxa Selic $\quad 15$

2.2. Estrutura a termo da taxa de juros $\quad 16$

2.3. Formação de expectativas, racionalidade e mercados eficientes 18

2.4. Importância das expectativas de mercado 22

2.5. Expectativas dos operadores e previsões dos economistas 23

2.6. Pesquisa de expectativa de mercado no Brasil 26

3. Dados e Metodologia 28

4. Resultados 32

5. Conclusões 41

6. Referências bibliográficas 43

7. Apêndices 47

Apêndice I - Capacidade Preditiva do DI Futuro e do TOP 5 CP em
Relação ao CDI

Apêndice II - Capacidade Preditiva do DI Futuro e do TOP 5 MP em

Apêndice III - Capacidade Preditiva do DI Futuro e do TOP 5 LP em

Relação ao CDI 49 


\section{Lista de Tabelas}

Tabela 1 - Ajuste Realizado para Utilização de dados do DI futuro

Tabela 2 - Volatilidade das Taxas do DI Futuro e da Gerin

Tabela 3 - Medidas de Capacidade Preditiva do DI Futuro e da Taxa Gerin em Relação ao CDI

Tabela 4 - Percentual de Observações da Gerin e do DI Futuro como Melhor Preditor do CDI em Ciclos de Alta, e Baixa e Manutenção da Taxa de Juros

Tabela 5 - REQM do DI Futuro e da Taxa Gerin em Relação do CDI em Ciclos de Alta, e Baixa e Manutenção da Taxa de Juros 


\section{Lista de Gráficos}

Gráfico 1 - Capacidade Preditiva do DI Futuro e da Taxa Gerin em Relação ao CDI

Gráfico 2 - Diferença de Erros de Previsão entre o DI Futuro e a Gerin

35

Gráfico 3 - Percentual de Observações da Gerin como Melhor Preditor do CDI

Gráfico 4 - Evolução da Capacidade Preditiva da Gerin e DI Futuro para 12 Meses

Gráfico 5 - Comportamento dos Preditores em Relação à Oscilação do CDI para Previsões de 9 meses 


\section{Siglas}

BCB - Banco Central do Brasil

BM\&FBovespa - Bolsa de Valores, Mercadorias e Futuros

CETIP - Câmara de Custódia e Liquidação

CDI - Certificado de Depósito Interbancário

Copom - Comitê de Política Monetária

DI - Depósito interfinanceiro

DMA - Desvio Médio Absoluto

EQM - Erro Quadrático Médio

ETTJ - Estrutura a Termo da Taxa de Juros

Fed - Federal Reserve

Focus - Relatório de mercado do Banco Central do Brasil

Gerin - Gerência-Executiva de Relacionamento com Investidores

SELIC - Sistema Especial de Liquidação e de Custódia

Top 5 - ranking Top Five

Top 5 CP - ranking Top 5 Curto Prazo

Top 5 MP - ranking Top 5 Médio Prazo

Top 5 LP - ranking Top 5 Longo Prazo 
Quantas chances desperdicei, Quando o que eu mais queria Era provar pra todo mundo Que eu não precisava Provar nada pra ninguém. (Quase sem querer) Renato Russo. 